\title{
Hypoplastic left heart syndrome: from comfort care to long-term survival
}

\author{
Mouhammad Yabrodi' and Christopher W. Mastropietro'
}

The management of hypoplastic left heart syndrome (HLHS) has changed substantially over the past four decades. In the 1970s, children with HLHS could only be provided with supportive care. As a result, most of these unfortunate children died within the neonatal period. The advent of the Norwood procedure in the early 1980s has changed the prognosis for these children, and the majority now undergoing a series of three surgical stages that can support survival beyond the neonatal period and into early adulthood. This review will focus on the Norwood procedure and the other important innovations of the last half century that have improved our outlook toward children born with HLHS.

$\mathbf{H}$ ypoplastic left heart syndrome (HLHS) is defined as underdevelopment of the structures of the left side of the heart, which includes the mitral valve, left ventricle, aortic valve, and aortic arch. HLHS occurs $0.16-0.36$ per 1,000 live births and comprises $1.4-3.8 \%$ of congenital heart disease. Despite the relatively low incidence, it is responsible for $23 \%$ of cardiac deaths occurring in the first week of life $(1,2)$. Prior to the 1980s, there were no viable surgical options for these infants. Rather, these infants were provided supportive care and comfort measures, and most died shortly after birth. Fortunately, as a result of surgical and medical advances of the last four decades, many of these children now undergo a series of three operations that allow them not only to survive infancy but also to live on into early adulthood. In this review, we will (i) present a historical perspective of HLHS; (ii) describe the Norwood operation, the most important breakthrough in the management of HLHS; (iii) discuss important modifications of this innovative surgical approach; (iv) review additional developments that have contributed substantially to the improved outcomes in patients with HLHS; and (v) explain the second and third surgical procedures necessary to sustain their lives beyond infancy.

\section{Historical Perspective}

In 1952, Lev first described a left hypoplastic heart malformation as underdevelopment of the left-sided cardiac chambers along with a small ascending aorta and aortic arch. This defect was not introduced as a syndrome until 1958 when Noonan and Nadas described it as a combined aortic and mitral atresia malformation $(3,4)$. At birth, an infant with this anatomy can survive as long as the ductus arteriosus (DA) remains patent and a communication between the left and right atria is present, allowing the right ventricle to maintain cardiac output to the systemic circulation (Figure 1). If the DA closes, systemic blood flow is compromised and clinical deterioration rapidly ensues. In 1979, Yabek and Mann described the first reported use of prostaglandin $\mathrm{E}_{1}\left(\mathrm{PGE}_{1}\right)$ to maintain ductal patency in a patient with HLHS (5). Continuous infusion of $\mathrm{PGE}_{1}$, however, is not a long-term solution. Indeed, regarding the use

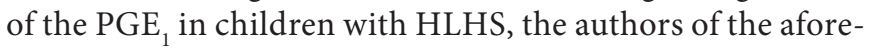
mentioned case report concluded "Although this entity is universally fatal, the transient palliation and improvement which resulted allowed us to exclude potentially correctable defects." (5).

As the field of pediatric cardiovascular surgery evolved, efforts were directed toward discovering a surgical strategy that could allow children to live without the necessity of PGE $_{1}$ and therefore support long-term viability. In 1970, Cayler et al. reported their approach in a neonate with hypoplastic left heart and an adequately sized aorta (6). In this patient, the ascending aorta was anastomosed to the right pulmonary artery to augment blood flow to the systemic circulation and the pulmonary arteries were banded distal to this anastomosis to limit pulmonary blood flow to the lung. This patient survived until 7 mo of age, but had limited applicability because the aortas in the majority of patients with HLHS are diminutive. In 1977, Doty and Knott described their approach in five neonates in which pulmonary venous return to the left atrium was baffled to the tricuspid valve, the main pulmonary artery was transected and connected to the aortic arch via a conduit, and the distal pulmonary artery was anastomosed to the right atrium to allow for passive pulmonary blood flow (7). All five of these infants died as a result of inadequate right ventricular function or compromised coronary blood flow. 


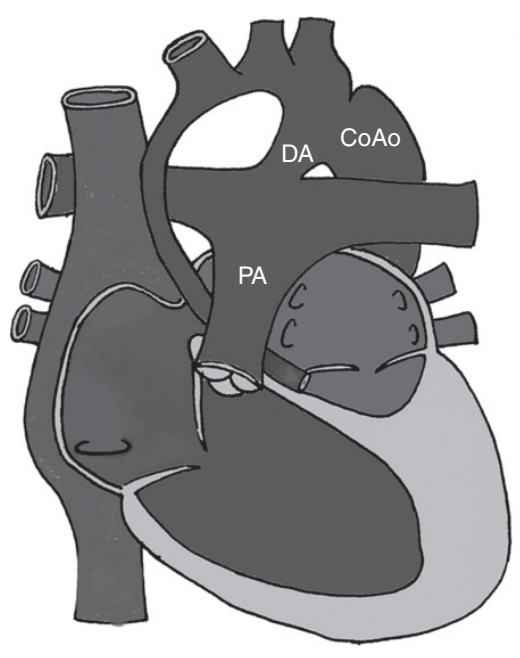

Figure 1. Hypoplastic left heart syndrome. At birth, children with hypoplastic left heart depend upon blood pumped by the right ventricle into the pulmonary artery (PA) to supply blood to the systemic circulation and end organs via a patent ductus arteriosus (DA). In many cases, coarctation of the aorta $(\mathrm{COAo})$ is also present.

\section{The Norwood Procedure}

In 1979, Norwood et al. were the first to establish a staged surgical management program for patients with HLHS (8). In 1983 , they reported the course of the first child in this program who was clinically well at 6 mo of life (8). This patient was full term newborn who was taken to operating room at $3 \mathrm{~d}$ of age for what would become known as the Norwood procedure. For this patient, an anastomosis between the proximal main pulmonary artery and the ascending aortic arch was established, and a 4 -mm polytetrafluorethylene shunt was placed connecting the new aortic arch to the pulmonary artery branches. This patient was discharged to home on the 18th postoperative day.

The importance of the Norwood procedure to children born with HLHS and the fields of pediatric cardiology, cardiovascular surgery, and cardiac intensive care cannot be understated. Since Norwood's momentous publication, the operation has steadily evolved into the standard of care for HLHS and not only has given hope to children born with this devastating lesion but also has catalyzed the development of modern pediatric cardiac intensive care units. The aim of the revolutionary procedure is to use the right ventricle as the main pumping chamber for support of the system circulation. To be able to achieve this goal, the following steps are required (Figure 2): (i) the atrial septum must be removed to secure good atrial communication, which is required to permit pulmonary venous return to reach the right ventricle; (ii) a connection between the right ventricle and aorta is created by reconstructing the aorta using the tissue of the proximal main pulmonary artery; (iii) a systemic-to-pulmonary artery shunt is placed between a branch of the aorta and branch of the pulmonary artery, to be the new source of pulmonary blood flow (and long-term replacement for the $\mathrm{PGE}_{1}$-dependent $\mathrm{DA}$ ) (8). At the conclusion of this operation, the right ventricle is pumping blood into a "neoaorta" and a portion of this blood is shunted to the pulmonary vasculature bed. In other words, the right ventricle is

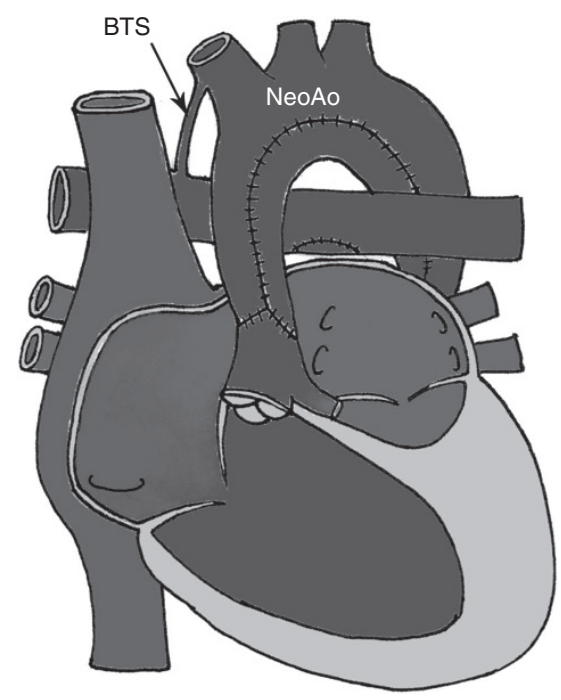

Figure 2. Hypoplastic left heart syndrome following the Norwood Procedure. A neoaorta (NeoAo) is formed using the patient's native pulmonary artery. A Blalock-Taussig shunt (BTS) is surgically inserted, connecting the right subclavian artery to the pulmonary artery for pulmonary blood flow, and the ductus arteriosus is ligated.

tasked with providing blood to both circulations in parallel, as opposed to traditional two ventricle physiology where blood travels to the pulmonary circulation and systemic circulation in series. Ideally, blood flow generated by the single right ventricle will be "balanced," so that similar amounts of blood will flow to the pulmonary and systemic circulations, i.e., at a 1:1 ratio. A discussion regarding the many ways in which pulmonary and systemic blood flow can be manipulated, either medically or surgically, to ensure this optimal ratio is beyond the scope of this review.

In the unique Norwood anatomy and physiology, oxygenated pulmonary venous blood returning to the left atrium mixes with deoxygenated systemic venous blood returning to the right atrium, and this mixed blood then flows into the right ventricle, where it is pumped to the systemic and pulmonary circulations. As a result, typical arterial oxygen saturations for these children are in the range of $75-85 \%$. These lower arterial oxygen saturations (as compared with normal individuals) are surprisingly well-tolerated. In fact, the ability for these neonates to adapt to and tolerate this "unnatural" physiology is one of the more fascinating aspects of contemporary pediatric cardiology and one of the more confusing notions for care providers unfamiliar with HLHS and the Norwood procedure.

The systemic-to-pulmonary artery shunt used by Norwood was a modification of the Blalock-Taussig (B-T) shunt, first famously described by Alfred Blalock and Helen Taussig in $1945(9,10)$. This type of shunt, which is still commonly used today, is a polytetrafluorethylene tube that connects the right innominate or subclavian artery to the right pulmonary artery and is required because the main pulmonary artery is utilized to create the neoaorta (8). As pulmonary vascular resistance and pulmonary arterial pressure are typically lower than systemic vascular resistance and arterial blood pressure, blood flows through the shunt from the innominate or subclavian 


\section{\begin{tabular}{l|l} 
Review & Yabrodiand Mastropietro
\end{tabular}}

artery to the right pulmonary artery. The shunt is typically 3.5 or $4 \mathrm{~mm}$ in diameter, depending on the size of the child, and under optimal circumstances, should act as a fixed resistor that prevents the undesirable clinical scenario of excessive pulmonary blood flow with inadequate systemic blood flow. If blood flow through the shunt does become excessive, even transiently, systemic blood flow, and coronary perfusion can be compromised. This phenomenon is referred to as "coronary steal," which can result in decreased myocardial function, malignant arrhythmias, and sudden cardiac death (11). On the other hand, acute shunt thrombosis, either partial or complete, is also a well-described complication that results in obstruction to pulmonary blood flow and profound life-threatening hypoxemia (12).

As an alternative to this tenuous shunt physiology, there have been many attempts to create a direct connection between right ventricle and pulmonary artery via a right ventricle-to-pulmonary artery (RV-to-PA) conduit (13). In 1981, prior to their landmark report of their successful Norwood procedure with modified B-T shunt placement, Norwood et al. tried utilizing nonvalved RV-to-PA conduits of varying sizes, but all patients died within $11 \mathrm{~h}$ after surgery due to either excessive pulmonary blood flow or cardiac failure (13). As a result of these early failures, the RV-to-PA conduit was overshadowed by the success of the B-T shunt until the late 1990s, when Shunji Sano revisited this notion. In 2003, Sano published his report of 19 infants with HLHS who undergo a "modified" Norwood procedure using a nonvalved polytetrafluorethylene RV-to-PA conduit instead of the traditional B-T shunt (14). Hospital survival was $89 \%$ and overall survival was $62 \%$, comparable to other reports of children who undergo the traditional Norwood procedure using a B-T shunt. From these encouraging results, interest in the "Sano shunt" had been piqued.

The main theoretical advantage of using an RV-to-PA conduit is the lesser degree of diastolic "run-off" blood flow as compared with the B-T shunt, leading to higher diastolic blood pressures and consequent improved coronary perfusion. There was hope that this advantage would translate into fewer early (and often sudden) deaths after the Norwood procedure, thought to be related in part to tenuous coronary blood flow (15). In contrast to the Norwood procedure with $\mathrm{B}$ - $\mathrm{T}$ shunt placement, however, the RV-to-PA conduit requires a right ventriculotomy (i.e., cutting into the ventricle to create an opening for the conduit), and the nonvalved nature of the conduit can lead to regurgitant flow. These theoretical disadvantages of the RV-to-PA conduit may increase the risk of ventricular arrhythmias, impair systemic right ventricle function, or cause volume overload (16-18). The excitement over the potential advantages and concern for the potential risks of the Sano shunt led to the seminal Single Ventricle Reconstruction (SVR) Trial (19).

\section{The SVR Trial}

Following Sano's pivotal work, many single-institution series were published comparing outcomes of the Norwood procedure with a traditional B-T shunt vs. the RV-to-PA conduit
$(15,20-23)$. Because of the conflicting nature of some of the data and the limitations inherent to single-center observations, a prospective randomized trial was needed to study this crucial question. Despite the logistical difficulties with conducting a large multicenter randomized controlled study in pediatric cardiac surgery, including the need for a large enough cohorts from which meaningful statistical analyses can be conducted, Ohye and numerous collaborators within the Pediatric Heat Network Investigators of North America were able to organize and complete the SVR trial (19).

The SVR trial, considered to be one of the most remarkable multicenter collaborations in any field of medicine in our current era, comprised more than 500 patients with HLHS enrolled from 15 centers randomized to a Norwood procedure with either a B-T shunt or RV-to-PA conduit. The trial was conducted between May 2005 and July 2008, with a primary outcome measure of death or cardiac transplant-free survival at 12 mo of age. Secondary outcomes were unintended cardiovascular interventions, right ventricular function, hospital course, and other serious adverse events. Transplant-free survival at $1 \mathrm{y}$ of age in the 274 infants who underwent the Norwood procedure with RV-to-PA conduit was $73.3 \%$, as compared with $63.6 \%$ in the 275 infants who undergo the Norwood procedure with B-T shunt, a statistically significant difference $(P$-value $=0.01)$. On the other hand, unintended cardiovascular interventions and postoperative complications were more common in patients with RV-to-PA conduits, and pulmonary artery growth, right ventricular-end diastolic size, and right ventricle ejection fraction over time were more favorable in patients with B-T shunts (19). Furthermore, the survival benefit of the RV-to-PA conduit over time became less apparent, with no significant difference in survival between the two groups when the all follow-up data (mean $32 \pm 11 \mathrm{mo}$ ) were analyzed.

In addition to these valuable data, the SVR trial has become a fruitful source of secondary analyses and follow-up studies, providing the pediatric cardiovascular community with a unique opportunity to continue to glean insight into the shortand long-term outcome of children with HLHS. Most recently, Oster et al. reviewed the SVR data and identified an association between digoxin, a medication that has been in existence for more than a century, and reduced mortality following hospital discharge after the Norwood procedure (24). This study is but one example of additional vital data being published from this landmark study, and part of the reason why an author recently wrote an editorial aptly entitled "The Single Ventricle Reconstruction Trial: The Gift that Keeps on Giving.” (25)

\section{The Hybrid Procedure}

Although the Norwood operation has become the standard of care for neonates born with HLHS, the complexity of the procedure and the need for cardiopulmonary bypass require that the neonate be somewhat clinically stable prior to the procedure. Some neonates such as those born very prematurely or those who develop life-threatening illnesses shortly after birth (e.g., necrotizing enterocolitis and neonatal sepsis) are deemed too sick to undergo the Norwood procedure. An alternative 
technique known as the hybrid procedure was first reported by Gibbs et al. in 1993. The less intensive approach combines interventional cardiac catheterization with off-cardiopulmonary bypass surgery (26). It achieves the same physiological objectives as the classic Norwood procedure in a less intensive manner, as follows: (i) pulmonary artery bands are placed on the right and left pulmonary arteries to increase the pressure in the main pulmonary artery, in attempt to prevent excessive pulmonary flow and ensure adequate systemic blood flow; (ii) patency of the ductal arteriosus is maintained with a stent placed by an interventional cardiologist; and (iii) unrestricted mixing or pulmonary and systemic venous return at atrial level is accommodated by performing either surgical atrial septectomy or balloon atrial septostomy (Figure 3). The timing of these procedures varies, dependent on center preference and patient condition (26-29).

Although children with HLHS who undergo the hybrid procedure have many physiologic similarities to those children who undergo the Norwood operation, the manner in which their coronary and cerebral circulations are perfused is notably different. After the Norwood operation, blood is ejected into the aorta and flows anterograde, directly providing perfusion to the coronary and cerebral vascular beds. In children with hybrid anatomy, blood ejected into the pulmonary artery traverses the DA and provides coronary and cerebral blood flow in a retrograde manner, through the native aortic arch (Figure 3). Accordingly, stenosis or obstruction can occur at the sight where the DA connects to the native aorta, a complication that is termed retrograde aortic arch obstruction $(30,31)$. The occurrence rate of retrograde aortic arch obstruction has been reported to be 10$24 \%$ and can have a significant impact on perfusion to these vital organs $(30,31)$. In fact, in patients in whom it occurs, especially early after the hybrid procedure, it has been associated increased mortality $(30,31)$. For these children, surgical conversion to Norwood anatomy may be warranted.

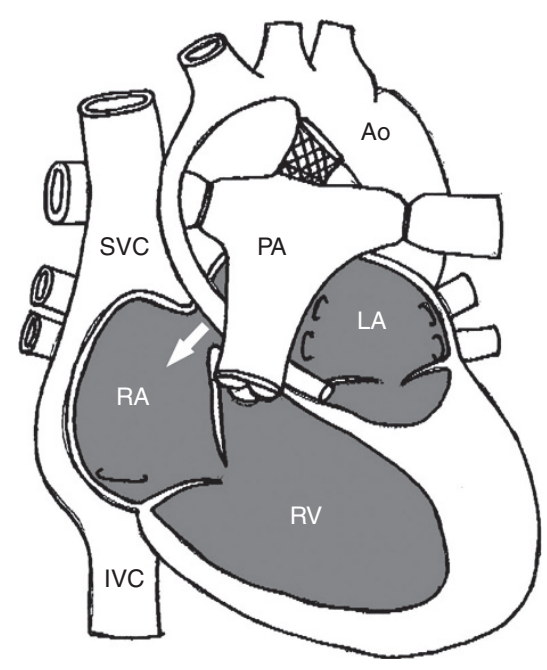

Figure 3. Hypoplastic left heart syndrome following the hybrid procedure. A stent is placed in the ductus arteriosus to maintain patency and bands are placed around the right and left pulmonary arteries to restrict pulmonary blood flow, thereby "balancing" the circulations. (Ao: aorta; IVC: inferior vena cava; LA: left atrium; PA: pulmonary artery; RA: right atrium; $\mathrm{RV}$ : right ventricle; SVC: superior vena cava)
Since its initial conception, the hybrid procedure has not only given tenuous neonates with HLHS a chance at survival, but has also been applied in other clinical scenarios. For example, the hybrid procedure has been applied to some children with HLHS who have a borderline left ventricle, which is a ventricle that is smaller than normal but has potential to grow large enough to allow for a two ventricle repair. In some of these children, the hybrid procedure has been used as a bridge to allow for time to determine if adequate left ventricle growth can occur $(32,33)$.

The avoidance of cardiopulmonary bypass is another appealing aspect of the hybrid procedure, as the use of cardiopulmonary bypass in the newborn period has been associated with abnormal neurocognitive development $(34,35)$. This potential (but unproven) advantage has, at least in part, prompted some institutions to apply the hybrid approach to the majority of their patients with HLHS (30). Galantowicz et al. were one of the first groups to truly embrace the hybrid procedure, reporting short-term survival of $90 \%$ in 40 patients with HLHS managed with this approach (30). More recently, Yerebakan et al. presented their experience of 182 patient with HLHS who undergo hybrid procedure, reporting an operative survival of $97.5 \%$ (36). Despite these encouraging results, most centers restrict use of the hybrid procedure to their most fragile neonates and rely on the more traditional and established Norwood procedure for the majority of their children with HLHS. The hybrid procedure will likely need to be subjected to more rigorous study, akin to what was accomplished with the SVR Trial, before more widespread application occurs.

\section{Interstage Monitoring}

Thus far, this review has focused on the innovations that have allowed many children with HLHS to survive the neonatal period and be successfully discharged to home after this surgical intervention. The Norwood procedure, however, represents only the first step toward a chance at long-term survival. These children ultimately require two additional surgical procedures, commonly referred to as the stage II and stage III surgeries. The period of time between hospital discharge after the Norwood procedure and the stage II surgery, commonly referred to as the interstage period, has been well-recognized as a period of considerably fragility. The risk of mortality during this time is high (8-12\%) (37-39), and death is often sudden and unexpected $(40,41)$. An analysis of the patients in the SVR trial identified prematurity, certain anatomic variations, and socioeconomic factors as independent risk factors for interstage mortality (38). The presence of a B-T shunt was also identified as a risk factor for interstage mortality in the subset of infants without moderate-to-severe atrioventricular valve regurgitation.

Close outpatient surveillance has thus far been shown to be the most effective means of minimizing interstage attrition in children with HLHS and has therefore become a crucial component of their care. Seminal work by Ghanayem et al. demonstrated improved survival after establishment of an intensive interstage home monitoring program for children with HLHS. 


\section{Review | Yabrodi and Mastropietro}

The interstage mortality was $0 \%$ after introduction of this home monitoring program at their institution and the improvement was sustained over a 10 -y period $(37,42)$. Their results have since led to the development of similar programs around the world $(39,43)$. These programs typically provide families with an infant scale and pulse oximeter for their homes, and require regular phone interviews and clinic appointments aimed at detecting early warning signs before clinical deterioration can occur. Moreover, many centers have established interstage multidisciplinary clinics to provide regular comprehensive assessments including meticulous evaluation of nutritional status and oral-motor feeding skills by specialized dieticians and speech therapists (44). On the other hand, a recently completed multicenter study by Oster et al. through the National Pediatric Cardiology Quality Improvement Collaborative database showed no association between daily weight and oxygen monitoring with mortality, heart transplantation, readmission, or weight gain (24). Hence, although there should be little debate regarding the positive impact of intensive interstage home monitoring on contemporary outcomes for children with HLHS, the value of each of the individual components of these programs remains unclear.

\section{The Stage II and III Operations}

Patients with HLHS require their stage II and III surgical procedures to convert their physiology from one volume overloaded ventricle pumping two circulations in parallel into physiology in which blood flows through the pulmonary and systemic circulations in series, thereby "unloading" the single ventricle such that it only has to pump one circulation. Effective pulmonary blood flow therefore must occur in the absence of a pulmonary ventricle. This seemingly insurmountable challenge was accomplished with the use of cavopulmonary anastomoses or shunts. The concept of a cavopulmonary shunt was first proposed by the Italian surgeon Carlon and his coworkers based on experiments using dogs and human cadavers (45). In 1958, William Glenn reported his first successful cavopulmonary shunt on a living human (46). The patient was a 7-y-old boy with a single cardiac ventricle, transposition of the great arteries and pulmonic stenosis. In what would become known as the classic Glenn operation, the right superior vena cava was anastomosed to the right pulmonary artery. In the current era, the procedure has been modified slightly and is commonly referred to as a bidirectional Glenn, and has become the standard of care as the second stage operation for patients with HLHS.

The bidirectional Glenn operation consists of connecting superior the vena cava to the cranial portion of right pulmonary artery to provide blood flow to both pulmonary branches (47) (Figure 4). This physiology can also be created with the hemi-Fontan operation, a modification of the bidirectional Glenn in which (i) the central pulmonary arteries undergo patch augmentation, (ii) a connection between the right atrialto-superior vena cava junction and pulmonary arteries is constructed, and (iii) patch closure of the right atrial-to-superior vena cava junction is completed, obviating the need to ligate

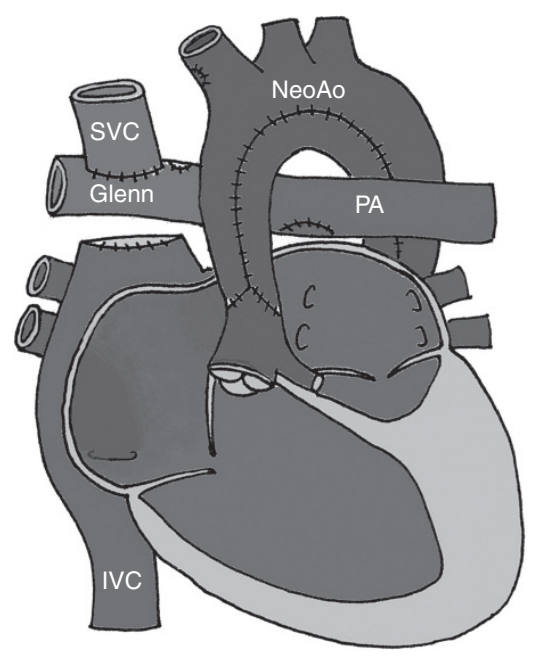

Figure 4. Stage II surgery for hypoplastic left heart syndrome-bidirectional Glenn: The superior vena cava (SVC) is transected and anastomosed to the pulmonary artery (PA). Cerebral and upper extremity blood passively flows to the lungs through the PA via the SVC. Oxygenated pulmonary venous blood then enters a common atrium, mixes with deoxygenated blood from the inferior vena cava (IVC), and enters the right ventricle where it is pumped through the neoaorta (NeoAo) to the systemic circulation.

the superior vena cava (48). Regardless of which technique is preferred, the overall results of stage II procedures have been excellent, exceeding 95\% in several large series (49).

In order for the superior cavopulmonary anastomosis to function appropriately, an infant's pulmonary vascular resistance and pulmonary arterial pressure must be low enough to permit the so-called "passive" pulmonary blood flow from the systemic venous system. Experience has suggested that beyond 3 mo of age, pulmonary vascular resistance is low enough in most infants to move forward with the stage II operation (50), although it has been performed in infants as young as 1 mo of age by programs focused on reducing the duration of the tenuous interstage period $(51,52)$. Regardless of the age at which the surgery is performed, several important physiologic changes occur following its completion. The unloaded single ventricle has reduced end diastolic volume (because it only needs to pump blood to one circulation), which decreases ventricular wall stress and improves function of the atrioventricular valve, both of which lead to more efficient ventricular function (53). In addition, the systemic-to-pulmonary artery shunt is no longer needed and thus ligated, decreasing diastolic run-off and thereby increasing diastolic blood pressure and coronary perfusion $(54,55)$. These physiologic improvements can allow patients, in many cases, to thrive for several years prior to their next (and hopefully final) surgical stage, known as the Fontan operation.

During the stage II operation, only systemic venous return from the upper body is directed into the pulmonary circulation via the superior cavopulmonary anastomosis. Systemic venous return from the lower body continues to flow into the right atrium via the inferior vena cava, mixing with pulmonary venous return and resulting in arterial oxygen saturations of 


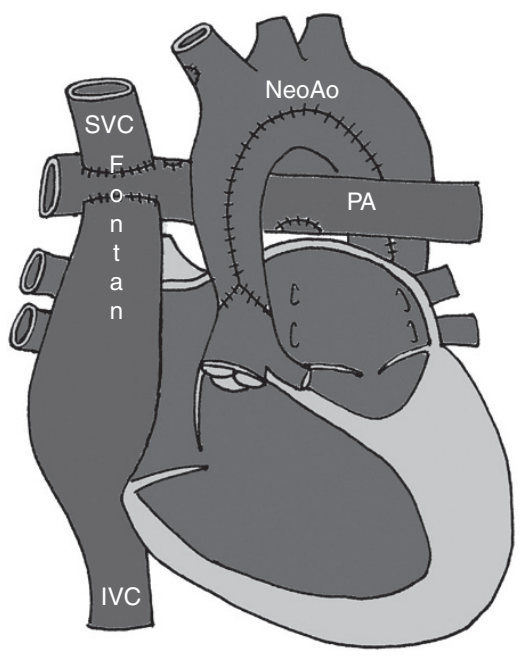

Figure 5. Stage III surgery for hypoplastic left heart-Lateral Tunnel Fontan: Deoxygenated blood returning to the right atrium via the inferior vena cava (IVC) is baffled within the right atrium to the superior vena cava (SVC), at which point all systemic venous return flows passively to the lungs via the pulmonary arteries (PAs). The circulation is now completely in series.

$70-90 \%$. As patients grow from infants to toddlers, and oxygen consumption in the lower portion of the body increases, a greater amount of desaturated blood flows into the right atrium via the inferior vena cava. As a result, progressive cyanosis can occur and can dictate the need for their Fontan operation. The concept of the Fontan operation was first applied to a patient with tricuspid atresia by Francis Fontan in 1968 (56), but has since become the final surgical stage for patients with HLHS. The goal of this ingenious operation is to direct the desaturated systemic venous return the inferior vena cava into the pulmonary circulation, which can be done either via a lateral tunnel (Figure 5) or extracardiac conduit that connects the inferior vena cava to the pulmonary artery $(57,58)$. In some patients, small fenestration may be created in the Fontan conduit, a modification aimed at providing children with this unique anatomy and physiology with another means to fill their single ventricle, albeit with desaturated blood (59). This practice may be especially helpful in patients with relatively high pulmonary vascular pressures, although studies attempting to discern the merits of these theoretical benefits have been conflicting $(60,61)$.

\section{Long-Term Complications}

Despite the aforementioned advancements, patients with HLHS have considerable long-term morbidity following their Fontan operation, and early mortality is not uncommon (62). In a recent single center report, only $40 \%$ of children with HLHS who survived through all three surgical stages were alive at $10 \mathrm{y}$ after their Fontan operation (63). High systemic venous pressures, abnormal ventricular morphology, thromboembolic events, and recurrent arrhythmias can create a tremendous burden of disease for these children $(64,65)$. Exercise intolerance, congestive heart failure, hepatic dysfunction, and disease processes more specific to patients with Fontan physiology such as protein-losing enteropathy and plastic bronchitis are additional complications that can occur and further negatively impact their quality of life $(64,65)$. As short-term outcomes continue to improve, efforts to better understand and manage these long-term challenges will likely become the dominant focus of research for these unique children.

\section{Fetal Intervention}

Another exciting development in the management of HLHS is fetal cardiac intervention, which has emerged as a possible means of altering the natural history of significant cardiac anomalies in utero, with the ultimate goal of improving survival and long-term outcomes. In 1991, Maxwell et al. published their experience with in utero dilation of the aortic valves of two patients with severe aortic stenosis. Since this report, there have been an increasing number of centers across the world who are attempting fetal cardiac interventions, most often for severe aortic stenosis (66). Since many fetuses with severe aortic stenosis will eventually be born with HLHS, clinicians hope to prevent this progression with early fetal intervention. In 2010, International Fetal Cardiac Intervention Registry was established to collect data on all fetal cardiac intervention to learn from the combined experience of all centers (67). As more data from this registry become available, optimal candidates for fetal cardiac intervention may be identified, with the goal of maximizing impact while minimizing risk.

\section{CONCLUSION}

Prior to the original breakthroughs of Norwood and his colleagues, children born with HLHS had less chance of survival. In the current era, because of Dr Norwood's work and that of many others who have devoted their careers to improving outcomes in these children, survival beyond the neonatal period and into adulthood is not only possible but also commonplace. Morbidity and mortality in patients with HLHS, however, when compared with other congenital heart lesions, remain relatively high, indicating that much more work is needed. Moreover, as these children continue to survive longer, a better understanding of the long-term complications related to their unique physiology is imperative. Fortunately, the remarkable progress that has occurred over the last four decades, from comfort care to long-term survival, should make patients with HLHS, their families, and the physicians who care for them hopeful that outcomes will continue to improve.

\section{STATEMENT OF FINANCIAL SUPPORT None.}

Disclosure: The authors have no conflicts of interest or financial ties to any products discussed in this article.

\section{REFERENCES}

1. Report of the New England Regional Infant Cardiac Program. Pediatrics 1980;65:375-461.

2. Samánek M, Slavík Z, Zborilová B, Hrobonová V, Vorísková M, Skovránek J. Prevalence, treatment, and outcome of heart disease in liveborn children: a prospective analysis of 91,823 live-born children. Pediatr Cardiol 1989;10:205-11.

3. Lev M. Pathologic anatomy and interrelationship of hypoplasia of the aortic tract complexes. Lab Invest 1952;1:61-70. 
4. Noonan JA, Nadas AS. The hypoplastic left heart syndrome; an analysis of 101 cases. Pediatr Clin North Am 1958;5:1029-56.

5. Yabek SM, Mann JS. Prostaglandin E1 infusion in the hypoplastic left heart syndrome. Chest 1979;79:330-1.

6. Cayler GG, Smeloff EA, Miller GE Jr. Surgical palliation of hypoplastic left side of the heart. N Engl J Med 1970;282:780-3.

7. Doty DB, Knott HW. Hypoplastic left heart syndrome. Experience with an operation to establish functionally normal circulation. J Thorac Cardiovasc Surg 1977;74:624-30.

8. Norwood WI, Lang P, Hansen DD. Physiologic repair of aortic atresiahypoplastic left heart syndrome. N Engl J Med 1983;308:23-6.

9. Blalock A, Taussig H. The Surgical treatment of malformations of the heart in which there is pulmonary stenosis or pulmonary atresia. JAMA 1945;128:189-202.

10. Murphy AM, Cameron DE. The Blalock-Taussig-Thomas collaboration: a model for medical progress. JAMA 2008;300:328-30.

11. Donnelly JP, Raffel DM, Shulkin BL, et al. Resting coronary flow and coronary flow reserve in human infants after repair or palliation of congenital heart defects as measured by positron emission tomography. J Thorac Cardiovasc Surg 1998;115:103-10.

12. Bartram U, Grünenfelder J, Van Praagh R. Causes of death after the modified Norwood procedure: a study of 122 postmortem cases. Ann Thorac Surg 1997;64:1795-802.

13. Norwood WI, Lang P, Casteneda AR, Campbell DN. Experience with operations for hypoplastic left heart syndrome. J Thorac Cardiovasc Surg 1981;82:511-9.

14. Sano S, Ishino K, Kawada M, Honjo O. Right ventricle-pulmonary artery shunt in first-stage palliation of hypoplastic left heart syndrome. Semin Thorac Cardiovasc Surg Pediatr Card Surg Annu 2004;7:22-31.

15. Mair R, Tulzer G, Sames E, et al. Right ventricular to pulmonary artery conduit instead of modified Blalock-Taussig shunt improves postoperative hemodynamics in newborns after the Norwood operation. J Thorac Cardiovasc Surg 2003;126:1378-84.

16. Frommelt PC, Gerstenberger E, Cnota JF, et al.; Pediatric Heart Network Investigators. Impact of initial shunt type on cardiac size and function in children with single right ventricle anomalies before the Fontan procedure: the single ventricle reconstruction extension trial. J Am Coll Cardiol 2014;64:2026-35.

17. Newburger JW, Sleeper LA, Frommelt PC, et al.; Pediatric Heart Network Investigators. Transplantation-free survival and interventions at 3 years in the single ventricle reconstruction trial. Circulation 2014;129:2013-20.

18. Wilder TJ, McCrindle BW, Phillips AB, et al. Survival and right ventricular performance for matched children after stage-1 Norwood: Modified Blalock-Taussig shunt versus right-ventricle-to-pulmonary-artery conduit. J Thorac Cardiovasc Surg 2015;150:1440-50, 1452.e1-8; discussion $1450-2$.

19. Ohye RG, Sleeper LA, Mahony L, et al.; Pediatric Heart Network Investigators. Comparison of shunt types in the Norwood procedure for singleventricle lesions. N Engl J Med 2010;362:1980-92.

20. Mahle WT, Cuadrado AR, Tam VK. Early experience with a modified Norwood procedure using right ventricle to pulmonary artery conduit. Ann Thorac Surg 2003;76:1084-8; discussion 1089.

21. Sano S, Ishino K, Kado H, et al. Outcome of right ventricle-to-pulmonary artery shunt in first-stage palliation of hypoplastic left heart syndrome: a multi-institutional study. Ann Thorac Surg 2004;78:1951-7; discussion $1957-8$.

22. Tabbutt S, Dominguez TE, Ravishankar C, et al. Outcomes after the stage I reconstruction comparing the right ventricular to pulmonary artery conduit with the modified Blalock Taussig shunt. Ann Thorac Surg 2005;80:1582-90; discussion 1590-1.

23. Sano S, Huang SC, Kasahara S, Yoshizumi K, Kotani Y, Ishino K. Risk factors for mortality after the Norwood procedure using right ventricle to pulmonary artery shunt. Ann Thorac Surg 2009;87:178-85; discussion 185-6.

24. Oster ME, Ehrlich A, King E, et al. Association of interstage home monitoring with mortality, readmissions, and weight gain: a multicenter study from the National Pediatric Cardiology Quality Improvement Collaborative. Circulation 2015;132:502-8.
25. Jaquiss RD. The single ventricle reconstruction trial: the gift that keeps on giving. J Thorac Cardiovasc Surg 2016;151:676-7.

26. Gibbs JL, Wren C, Watterson KG, Hunter S, Hamilton JR. Stenting of the arterial duct combined with banding of the pulmonary arteries and atrial septectomy or septostomy: a new approach to palliation for the hypoplastic left heart syndrome. Br Heart J 1993;69:551-5.

27. Bacha EA, Daves S, Hardin J, et al. Single-ventricle palliation for high-risk neonates: the emergence of an alternative hybrid stage I strategy. J Thorac Cardiovasc Surg 2006;131:163-171.e2.

28. Murphy MO, Bellsham-Revell H, Morgan GJ, et al. Hybrid procedure for neonates with hypoplastic left heart syndrome at high-risk for norwood: midterm outcomes. Ann Thorac Surg 2015;100:2286-90; discussion 2291-2.

29. Pizarro C, Derby CD, Baffa JM, Murdison KA, Radtke WA. Improving the outcome of high-risk neonates with hypoplastic left heart syndrome: hybrid procedure or conventional surgical palliation? Eur J Cardiothorac Surg 2008;33:613-8.

30. Galantowicz M, Cheatham JP, Phillips A, et al. Hybrid approach for hypoplastic left heart syndrome: intermediate results after the learning curve. Ann Thorac Surg 2008;85:2063-70; discussion 2070-1.

31. Stoica SC, Philips AB, Egan M, et al. The retrograde aortic arch in the hybrid approach to hypoplastic left heart syndrome. Ann Thorac Surg 2009;88:1939-46; discussion 1946-7.

32. Davis CK, Pastuszko P, Lamberti J, Moore J, Hanley F, El Said H. The hybrid procedure for the borderline left ventricle. Cardiol Young 2011;21: 26-30.

33. Yerebakan C, Murray J, Valeske K, et al. Long-term results of biventricular repair after initial Giessen hybrid approach for hypoplastic left heart variants. J Thorac Cardiovasc Surg 2015;149:1112-20; discussion 1120-2.e2.

34. Licht DJ, Shera DM, Clancy RR, et al. Brain maturation is delayed in infants with complex congenital heart defects. J Thorac Cardiovasc Surg 2009;137:529-36; discussion 536-7.

35. Mahle WT, Tavani F, Zimmerman RA, et al. An MRI study of neurological injury before and after congenital heart surgery. Circulation 2002;106( 12 Suppl 1):I109-14.

36. Yerebakan C, Valeske K, Elmontaser H, et al. Hybrid therapy for hypoplastic left heart syndrome: Myth, alternative, or standard? J Thorac Cardiovasc Surg 2016;151:1112-21, 1123.e1-5.

37. Ghanayem NS, Hoffman GM, Mussatto KA, et al. Home surveillance program prevents interstage mortality after the Norwood procedure. J Thorac Cardiovasc Surg 2003;126:1367-77.

38. Ghanayem NS, Allen KR, Tabbutt S, et al.; Pediatric Heart Network Investigators. Interstage mortality after the Norwood procedure: results of the multicenter Single Ventricle Reconstruction trial. J Thorac Cardiovasc Surg 2012;144:896-906.

39. Furck AK, Uebing A, Hansen JH, et al. Outcome of the Norwood operation in patients with hypoplastic left heart syndrome: a 12-year single-center survey. J Thorac Cardiovasc Surg 2010;139:359-65.

40. Ohye RG, Schonbeck JV, Eghtesady P, et al.; Pediatric Heart Network Investigators. Cause, timing, and location of death in the Single Ventricle Reconstruction trial. J Thorac Cardiovasc Surg 2012;144:907-14.

41. Cashen K, Gupta P, Lieh-Lai M, Mastropietro C. Infants with single ventricle physiology in the emergency department: are physicians prepared? J Pediatr 2011;159:273-7.e1.

42. Rudd NA, Frommelt MA, Tweddell JS, et al. Improving interstage survival after Norwood operation: outcomes from 10 years of home monitoring. J Thorac Cardiovasc Surg 2014;148:1540-7.

43. Petit CJ, Fraser CD, Mattamal R, Slesnick TC, Cephus CE, Ocampo EC. The impact of a dedicated single-ventricle home-monitoring program on interstage somatic growth, interstage attrition, and 1-year survival. J Thorac Cardiovasc Surg 2011;142:1358-66.

44. Kelleher DK, Laussen P, Teixeira-Pinto A, Duggan C. Growth and correlates of nutritional status among infants with hypoplastic left heart syndrome (HLHS) after stage 1 Norwood procedure. Nutrition 2006;22: 237-44.

45. Mondini PG, Carlon CA, de Marchi R. Method of performing anastomosis between the superior vena cava and the right branch of the pul- 
monary artery; operative technic and experimental research. G Ital Chir 1950;6:775-91.

46. Glenn WW. Circulatory bypass of the right side of the heart. IV. Shunt between superior vena cava and distal right pulmonary artery; report of clinical application. N Engl J Med 1958;259:117-20.

47. Bridges ND, Jonas RA, Mayer JE, Flanagan MF, Keane JF, Castaneda AR. Bidirectional cavopulmonary anastomosis as interim palliation for highrisk Fontan candidates. Early results. Circulation 1990;82(5 Suppl IV): 170-6.

48. Douville EC, Sade RM, Fyfe DA. Hemi-Fontan operation in surgery for single ventricle: a preliminary report. Ann Thorac Surg 1991;51:893-9; discussion 900.

49. Bove EL, Lloyd TR. Staged reconstruction for hypoplastic left heart syndrome. Contemporary results. Ann Surg 1996;224:387-94; discussion 394-5.

50. Chang AC, Hanley FL, Wernovsky G, et al. Early bidirectional cavopulmonary shunt in young infants. Postoperative course and early results. Circulation 1993;88(5 Pt 2):II149-58.

51. Petrucci O, Khoury PR, Manning PB, Eghtesady P. Outcomes of the bidirectional Glenn procedure in patients less than 3 months of age. J Thorac Cardiovasc Surg 2010;139:562-8.

52. Jaquiss RD, Ghanayem NS, Hoffman GM, et al. Early cavopulmonary anastomosis in very young infants after the Norwood procedure: impact on oxygenation, resource utilization, and mortality. J Thorac Cardiovasc Surg 2004;127:982-9.

53. Mahle WT, Cohen MS, Spray TL, Rychik J. Atrioventricular valve regurgitation in patients with single ventricle: impact of the bidirectional cavopulmonary anastomosis. Ann Thorac Surg 2001;72:831-5.

54. Jacobs ML, Rychik J, Rome JJ, et al. Early reduction of the volume work of the single ventricle: the hemi-Fontan operation. Ann Thorac Surg 1996;62:456-61; discussion 461-2.

55. Fogel MA, Rychik J, Vetter J, Donofrio MT, Jacobs M. Effect of volume unloading surgery on coronary flow dynamics in patients with aortic atresia. J Thorac Cardiovasc Surg 1997;113:718-26; discussion 726-7.

56. Fontan F, Baudet E. Surgical repair of tricuspid atresia. Thorax 1971;26: 240-8.

57. Stamm C, Friehs I, Mayer JE Jr, et al. Long-term results of the lateral tunnel Fontan operation. J Thorac Cardiovasc Surg 2001;121:28-41.

58. Marcelletti C, Corno A, Giannico S, Marino B. Inferior vena cava-pulmonary artery extracardiac conduit. A new form of right heart bypass. J Thorac Cardiovasc Surg 1990;100:228-32.
59. Bridges ND, Mayer JE Jr, Lock JE, et al. Effect of baffle fenestration on outcome of the modified Fontan operation. Circulation 1992;86:1762-9.

60. Lemler MS, Scott WA, Leonard SR, Stromberg D, Ramaciotti C. Fenestration improves clinical outcome of the fontan procedure: a prospective, randomized study. Circulation 2002;105:207-12.

61. Hsu DT, Quaegebeur JM, Ing FF, Selber EJ, Lamour JM, Gersony WM. Outcome after the single-stage, nonfenestrated Fontan procedure. Circulation 1997;96(9 Suppl II): 335-40.

62. Khairy P, Fernandes SM, Mayer JE Jr, et al. Long-term survival, modes of death, and predictors of mortality in patients with Fontan surgery. Circulation 2008;117:85-92.

63. Pundi KN, Johnson JN, Dearani JA, et al. 40-year follow-up after the Fontan operation: long-term outcomes of 1,052 patients. J Am Coll Cardiol 2015;66:1700-10.

64. Feinstein JA, Benson DW, Dubin AM, et al. Hypoplastic left heart syndrome: current considerations and expectations. J Am Coll Cardiol 2012;59(1 Suppl):S1-42.

65. Mastropietro CW, Clark JA, Grimaldi LM, Killinger JS, Richmond M. The patient with a single cardiac ventricle. Curr Pediatr Rev 2012;8:253-76.

66. Maxwell D, Allan L, Tynan MJ. Balloon dilatation of the aortic valve in the fetus: a report of two cases. Br Heart J 1991;65:256-8.

67. Moon-Grady AJ, Morris SA, Belfort M, et al.; International Fetal Cardiac Intervention Registry. International fetal cardiac intervention registry: a worldwide collaborative description and preliminary outcomes. J Am Coll Cardiol 2015;66:388-99.

This work is licensed under a Creative Commons Attribution-NonCommercial-NoDerivs $\quad 4.0$ International License. The images or other third party material in this article are included in the article's Creative Commons license, unless indicated otherwise in the credit line; if the material is not included under the Creative Commons license, users will need to obtain permission from the license holder to reproduce the material. To view a copy of this license, visit http://creativecommons.org/ licenses/by-nc-nd/4.0/

(c) The Author(s) (2016) 